\title{
International Consortium for Health Outcomes Measurement (ICHOM)
}

\author{
Thomas A Kelley \\ From The Core Outcome Measures in Effectiveness Trials (COMET) Initiative \\ Calgary, Canada. 20-21 May 2015
}

\section{Introduction}

Outcomes that reflect what matter most to patients are infrequently measured in clinical practice. When they are captured, the definitions used often vary between countries, making global comparisons and learning impossible. A similar challenge exists in clinical trial endpoints.

\section{Methods}

ICHOM was founded in 2012 to address these challenges. ICHOM brings together working groups, organised around the medical condition, consisting of patients, health professionals, researchers, outcomes measurement experts and policy makers, from all major regions of the world. Working groups follow a structured series of teleconferences, facilitated by ICHOM, with each teleconference covering a set topic, followed by a survey for working group members to complete. The end result is a globally agreed set of outcomes that reflects what matters most to most patients. ICHOM sets aim to be used in both routine clinical practice and as an endpoint in clinical studies.

\section{Results}

ICHOM has now produced 12 standard sets of outcomes covering approximately $35 \%$ of the global burden of disease. These sets include: cataracts; localised and advanced prostate cancer; lower back pain; coronary artery disease; Parkinson's disease; cleft lip and palate; stroke; macular degeneration; hip and knee osteoarthritis; depression and anxiety; lung cancer. ICHOM is now forming networks of hospitals around the world, which are working together to begin measuring, benchmarking, and performing outcome comparisons and translating this into subsequent learning.

Correspondence: T.Kelley@ichom.org

International Consortium for Health Outcomes Measurement, London, UK

\section{Conclusion}

ICHOM is working with health systems and measurement bodies all over the world to produce and implement, in clinical practice and in clinical studies, globally agreed standard sets of outcomes that reflect what matter most to patients. This will enable global outcome comparisons and translatable learning.

Published: 24 November 2015

doi:10.1186/1745-6215-16-S3-O4

Cite this article as: Kelley: International Consortium for Health Outcomes Measurement (ICHOM). Trials 2015 16(Suppl 3):O4.

\section{Submit your next manuscript to BioMed Central and take full advantage of: \\ - Convenient online submission \\ - Thorough peer review \\ - No space constraints or color figure charges \\ - Immediate publication on acceptance \\ - Inclusion in PubMed, CAS, Scopus and Google Scholar \\ - Research which is freely available for redistribution

() Biomed Central

(c) 2015 Kelley This is an Open Access article distributed under the terms of the Creative Commons Attribution License (http:// creativecommons.org/licenses/by/4.0), which permits unrestricted use, distribution, and reproduction in any medium, provided the original work is properly cited. The Creative Commons Public Domain Dedication waiver (http://creativecommons.org/publicdomain/
zero/1.0/) applies to the data made available in this article, unless otherwise stated. 